\title{
A Budget Impact Analysis of the Collaborative Care Model for Treating Opioid Use Disorder in Primary Care
}

\author{
Chuan Mei Lee, MD, MA ${ }^{7}$, Claudia Scheuter, $M D^{1,2}$, Danielle Rochlin, $M D^{7}$, \\ Terry Platchek, $M D^{7}$, and Robert M. Kaplan, $P h D^{7}$
}

${ }^{1}$ Clinical Excellence Research Center, Stanford University, Stanford, CA, USA; ${ }^{2}$ Division of General Internal Medicine, Inselspital Bern University Hospital, Bern, Switzerland.

J Gen Intern Med 34(9):1693-4 DOI: $10.1007 / \mathrm{s} 11606-019-04998-5$

(C) Society of General Internal Medicine 2019

\section{INTRODUCTION}

Opioid use disorder (OUD) affects an estimated 2.1 million people in the USA. ${ }^{1}$ The Collaborative Care Model (CoCM) can be used to treat OUD in primary care by adding a behavioral health manager to coordinate services and to offer brief psychotherapy, and a psychiatric consultant to assist when a patient is not progressing as expected. ${ }^{2} \mathrm{~A}$ randomized controlled trial (RCT) using CoCM found increased utilization of treatment (39.0\% vs $16.8 \%)$ and abstinence from opioids or alcohol at 6 months compared to usual care $(32.8 \%$ vs $22.3 \%)^{3}$

We performed a budget impact analysis on the expected increases in the expenditure of a health care system after the adoption CoCM to address OUD.

\section{METHODS}

The analysis was from the administrative perspective of an atrisk, 100,000-member system that serves Medicaid patients and followed the International Society for Pharmacoeconomics and Outcomes Research (ISPOR) guidelines. ${ }^{4}$ We estimated 1 -year costs and savings using published literature and structured interviews with content experts as detailed in Table 1. Treatment effects were derived from an $\mathrm{RCT}^{2}$ We modeled treatment with buprenorphine, which is currently less costly than extended-release injectable naltrexone. We calculated a break-even point where the total health care savings generated by OUD treatment offset the cost of the intervention. All amounts were adjusted to 2017 US dollars using the US Consumer Price Index.

We used Monte Carlo simulation methods to estimate confidence intervals allowing variation in several parameters to address uncertainty. The prevalence of OUD diagnosis was estimated at $0.89 \%$ (SD 0.6\%), and the percentage uptake was assumed to be $25 \%$ (SD 8\%). To model these variables, we used the beta cumulative probability distribution, solving for

Published online April 22, 2019 alpha and beta using the method described by VazquezReina. ${ }^{6}$

Hourly wages for psychiatrists $(\$ 103.89, \mathrm{SD} \$ 14)$ and $\mathrm{RN}$ care managers $(\$ 45.97, \mathrm{SD} \$ 7)$ were derived from the Bureau of Labor Statistics and were assumed to be normally distributed truncated at 2 standard deviations above and below the mean. Savings without medication were estimated at \$2540 (SD \$800), based on results from a Vermont Medicaid study. ${ }^{5}$ In the base case, the cost of buprenorphine per patient was fixed at $\$ 1164.67$, and the panel size was set at 85 . A dataset was generated with 1000 trials for each variable. Analyses were performed using MS Excel for MAC Version 16.18, and Monte Carlo simulations were performed using SIPmath Modeler (ProbabilityManagement.org).

\section{RESULTS}

The simulation model estimated that the cost per patient treated with a panel size of 85 was $\$ 2547$ (SD \$190; 95\% CI \$2173-\$2918) (Table 2). With a panel size of 85, the program would approximately breakeven but would have about a $14 \%$ chance of spending more than $\$ 200$ per patient, balanced by a $14 \%$ chance of gaining more than $\$ 200$ per patient. If the panel size is expanded to 120 , cost per patient treated declines to \$2145 (SD \$141; 95\% CI \$1867-\$2421), suggesting a likely positive balance.

\section{DISCUSSION}

Infrastructure to support CoCM requires an investment to hire and train personnel but increases capability to manage OUD. Adopting Medicare reimbursement rates by Medicaid and private payers would result in net positive revenue potential for primary care practices. ${ }^{7}$ We believe CoCM is likely to result in lower costs through decreased utilization of emergency department and inpatient hospital services. Integrating behavioral health services and OUD treatment in primary care practices appears justifiable in terms of both potential cost savings and patient benefits, although an RCT of CoCM did not show increased use of medication-assisted treatment. ${ }^{3}$ 
Table 1 Estimated Values and Sources for Key Variables

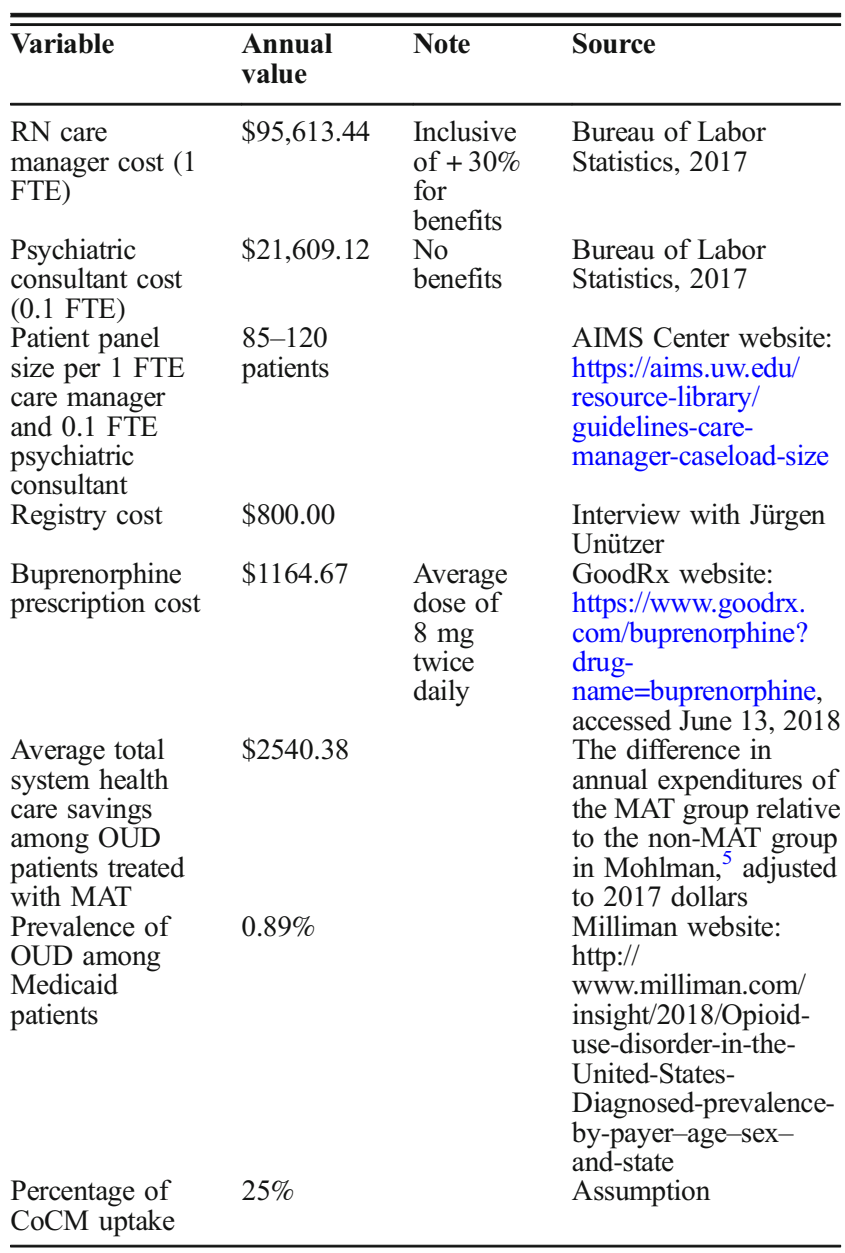

The Monte Carlo simulation builds variability around these estimates. As a result, some of the mean values in the simulation can differ very slightly (less than 1\%) from the values reported in this table

Our results are limited by uncertainty in our estimate of total health care savings among treated OUD patients. We extrapolated from a study on Medicaid expenditures in Vermont, ${ }^{5}$ which should be verified in larger studies. Personnel costs and buprenorphine costs may vary in different localities. Another concern is that our simulation was able to consider parameter

Table 2 Model Outcomes

\begin{tabular}{ll}
\hline \hline Variable & Value \\
\hline $\begin{array}{l}\text { Number of OUD patients assumed receiving CoCM } \\
\text { among 100,000 primary care patients }\end{array}$ & 223 \\
$\begin{array}{l}\text { Total program costs (including care manager, } \\
\text { psychiatrist, registry costs) }\end{array}$ & $\$ 308,336.83$ \\
$\begin{array}{l}\text { Program costs per patient without medication, assuming } \\
\text { a panel size of 85 }\end{array}$ & $\$ 1382.68$ \\
$\begin{array}{l}\text { Treatment costs per patient including the cost of } \\
\text { buprenorphine, assuming a panel size of 85 }\end{array}$ & $\$ 2547.35$ \\
$\begin{array}{l}\text { Program costs per patient without medication, assuming } \\
\text { a panel size of 120 }\end{array}$ & $\$ 980.44$ \\
\hline
\end{tabular}

uncertainties but not structural uncertainties. We assume the model is linear, but we do not know the true functional form.

Despite the limitations, our analysis suggests that the costs of a CoCM program are likely to be offset by savings if $25 \%$ of OUD patients receive treatment in a panel size of about 85 , while achieving better patient outcomes.

Acknowledgements: The authors would like to gratefully acknowledge Arnold Milstein, MD, MPH, and Brian Brady, MD, for their support of this work.

Corresponding Author: Chuan Mei Lee, MD, MA; Clinical Excellence Research Center, Stanford University, Stanford, CA, USA (e-mail: chuanmei@stanford.edu).

\section{Compliance with Ethical Standards:}

Conflict of Interest: The authors declare that they do not have a conflict of interest.

\section{REFERENCES}

1. Ahrnsbrak R, Bose J, Hedden S, Lipari R, Park-Lee E. Key substance use and mental health indicators in the United States: Results from the 2016 National Survey on Drug Use and Health (HHS Publication No. SMA 17-5044, NSDUH Series H-52). Center for Behavioral Health Statistics and Quality, Substance Abuse and Mental Health Services Administration (SAMHSA) NSDUH Data Review https://www.samhsa.gov/data/sites/ default/files/NSDUH-FFR1-2016/NSDUH-FFR1-2016htm. Published September. 2017. Accessed June 13, 2018

2. Unützer J, Harbin H, Schoenbaum MC, Druss BG. The Collaborative Care Model: An Approach for Integrating Physical and Mental Health Care in Medicaid Health Homes. Hamilton, NJ: Center for Health Care Strategies and Mathematica Policy Research; 2013/05// 2013.

3. Watkins KE, Ober AJ, Lamp $\mathbf{K}$, et al. Collaborative Care for Opioid and Alcohol Use Disorders in Primary Care: The SUMMIT Randomized Clinical Trial. JAMA Intern Med. 2017.

4. Sullivan SD, Mauskopf JA, Augustovski F, et al. Budget impact analysis-principles of good practice: report of the ISPOR 2012 Budget Impact Analysis Good Practice II Task Force. Value Health. 2014;17(1):514.

5. Mohlman MK, Tanzman B, Finison $\mathbf{K}$, Pinette M, Jones C. Impact of Medication-Assisted Treatment for Opioid Addiction on Medicaid Expenditures and Health Services Utilization Rates in Vermont. J Subst Abus Treat. 2016;67(Supplement C):9-14.

6. Vazquez-Reina A. Calculating the parameters of a Beta distribution using the mean and variance. 2018; https://www.govtrack.us/congress/bills/ 114/hr34.

7. Basu S, Landon BE, Williams JW Jr., Bitton A, Song Z, Phillips RS. Behavioral Health Integration into Primary Care: a Microsimulation of Financial Implications for Practices. J Gen Intern Med. 2017;32(12):13301341.

Publisher's Note Springer Nature remains neutral with regard to jurisdictional claims in published maps and institutional affiliations. 